\title{
Three gram sodium intake is associated with longer event-free survival only in patients with advanced heart failure
}

\author{
Terry A. Lennie, PhD, RN,FAAN, \\ University of Kentucky, College of Nursing \\ Eun Kyeung Song, PhD, RN, \\ Department of Nursing, College of Medicine, University of Ulsan \\ Jia-Rong $\mathrm{Wu}, \mathrm{PhD}, \mathrm{RN}$, \\ University of North Carolina at Chapel Hill, School of Nursing \\ Misook L. Chung, PhD, RN, \\ University of Kentucky, College of Nursing \\ Sandra B. Dunbar, DNS, \\ Emory University, School of Nursing \\ Susan J. Pressler, PhD, and \\ University of Michigan, School of Nursing \\ Debra K. Moser, DNSc, RN, FAAN \\ University of Kentucky, College of Nursing
}

\section{Abstract}

Background-There is limited evidence to support the recommendation that patients with heart failure (HF) restrict sodium intake. The purpose of this study was to compare differences in cardiac event-free survival between patients with sodium intake above and below $3 \mathrm{~g}$.

Methods-A total of 302 patients with HF (67\% male, 62 \pm 12 years, 54\% New York Heart Association [NYHA] class III/IV, ejection fraction $34 \pm 14 \%$ ) collected a 24-hour urine sodium (UNa) to indicate sodium intake. Patients were divided into 2 groups using a $3 \mathrm{~g}$ UNa cutpoint and stratified by NYHA class (I/II vs. III/IV). Event-free survival for 12-months was determined by patient or family interviews and medical record review. Differences in cardiac event-free survival were determined by Kaplan-Meier survival curve with log rank test and Cox hazard regression.

Results-The Cox regression hazard ratio for 24-hour UNa $\geq 3 \mathrm{~g}$ in NYHA class I/II was 0.44 (95\% confidence interval $[\mathrm{CI}]=.20-.97)$ and $2.54(95 \% \mathrm{CI}=1.10-5.84)$ for NYHA III/IV after controlling for age, gender, HF etiology, body mass index, ejection fraction, and total comorbidity score.

\footnotetext{
(C) 2010 Elsevier Inc. All rights reserved.

Corresponding Author: Terry A. Lennie, PhD, RN, FAAN, 521 College of Nursing, University of Kentucky, 751 Rose Street, Lexington, KY 40536-0232, Fax number, telephone number and email address, Phone: 859-323-6631, Fax 859-257-0554, tlennie@uky.edu.

Publisher's Disclaimer: This is a PDF file of an unedited manuscript that has been accepted for publication. As a service to our customers we are providing this early version of the manuscript. The manuscript will undergo copyediting, typesetting, and review of the resulting proof before it is published in its final citable form. Please note that during the production process errors may be discovered which could affect the content, and all legal disclaimers that apply to the journal pertain.

Disclosures

None.
} 
Conclusions-These data suggest that $3 \mathrm{~g}$ dietary sodium restriction may be most appropriate for patients in NYHA functional classes III and IV.

\section{Keywords}

Diet; Sodium Restriction; NYHA Class

\section{INTRODUCTION}

There is general agreement among nutrition guidelines that individuals without heart failure (HF) should limit sodium intake to less than $2.3 \mathrm{~g}$; while those with hypertension, blacks, and middle-aged and older adults should limit intake to $1.5 \mathrm{~g}$ of sodium per day.1, $2 \mathrm{In}$ contrast, there is a lack of consensus among the three major guidelines regarding the recommended level of dietary sodium intake for patients with compensated HF. The recommended limit in the Heart Failure Society of America (HFSA) guidelines is 2 to $3 \mathrm{~g}$ per day. 3 The former American College of Cardiology/American Heart Association guidelines included a recommendation to limit sodium intake to 3 to $4 \mathrm{~g}$ per day.4 In the most current guidelines however, only a nonspecific recommendation of moderate sodium restriction is provided.5 Similarly, the European Society of Cardiology guidelines provide only the nonspecific recommendation that sodium intake be limited when necessary.6 The evidence to support the recommendation for the general public was based on research for prevention and treatment of hypertension in individuals without cardiac dysfunction ${ }^{1,2}$ and may not be applicable to patients the HF. The level of evidence to support the recommendation in all HF guidelines was listed as level C, Expert Opinion, indicating limited supporting evidence. This limited evidence is likely responsible for the lack of consensus among HF guidelines and the trend toward providing only non-specific recommendations for sodium restriction.

Previous investigators have reported that fluid overload secondary to excessive dietary sodium intake is the most common reason for rehospitalization related to acute decompensated HF. $7^{-10}$ Excess dietary sodium intake in these studies was determined by patient self-report or medical record review. Thus, the actual level of sodium intake associated with hospitalization was not estimated in any prior study. In addition, most prior studies were published over ten years ago and may not reflect patient responses to dietary sodium intake under current management guidelines. Further, there is evidence that patients may respond differently to sodium restriction depending on symptom severity (i.e., New York Heart Association [NYHA] functional class). ${ }^{11}$ These potential differences have not been considered in previous research. Therefore, the purpose of this study was to compare differences in event-free survival among patients with sodium intake above and below $3 \mathrm{~g}$ stratified by NYHA functional class. The $3 \mathrm{~g}$ cut point was chosen because it represents the upper limit of sodium intake specified in the HFSA guidelines, 3 the only guidelines with a specific level of sodium restriction.

\section{METHODS}

\section{Design, Setting and Participants}

This was a prospective observational study of patients with HF recruited from outpatient clinics associated with six large community hospitals or academic medical centers in Kentucky, Georgia, Indiana, and Ohio.

A total of 349 patients were eligible for this study. One patient declined to participate, 7 patients withdrew, 3 patients were lost to follow-up, and 36 were determine to have incomplete 24-hour urines based on urine collection logs or $\mathrm{UNa}$ values below $40 \mathrm{mEq} / \mathrm{L} /$ day. ${ }^{12}$ Subsequently, a total of 302 patients were included in the study. Eligibility criteria for 
participation included: (1) confirmed diagnosis of chronic HF with either reduced left ventricular ejection faction (LVEF) $<40 \%$ or preserved LVEF $\geq 40 \%$, (2) on stable doses of medications for at least three months, and (3) able to read and speak English. Exclusion criteria were: (1) referred for heart transplantation, (2) history of acute myocardial infarction or cerebrovascular accident within the prior 3 months, (3) valvular heart disease, peripartum HF, myocarditis as primary HF etiology, (4) other known inflammatory processes, (5) endstage renal failure, or (6) co-existing terminal illness such as cancer.

\section{Measurements of variables}

Dietary sodium intake-The level of dietary sodium intake was estimated by measurement of 24-hour urinary sodium excretion (UNa). ${ }^{13}$ The measurement of 24-hour $\mathrm{UNa}$ is considered an objective indicator of dietary sodium intake. In individuals who do not perspire heavy, 24-hour UNa accounts for approximately $95 \%$ to $98 \%$ of dietary sodium intake14 and is correlated with dietary sodium intake measured by food diaries.15,16

Clinical variables-Age, gender, etiology of HF, NYHA functional class, left ventricular ejection fraction (LVEF), prescribed medications, and total comorbidity score using Charlson's comorbidity index ${ }^{17}$ were collected through patient interview and review of medical records. NYHA functional class was determined by a structured patient interview that determined symptom severity related to activities. Height and weight were measured by the trained research nurses using calibrated scales and professional grade stadiometers in the General Clinical Research Center (GCRC) at each site. Body mass index (BMI) was calculated as weight $(\mathrm{kg}) /$ height $\left(\mathrm{m}^{2}\right)$. The majority $(98 \%)$ of the patients prescribed diuretics were prescribed furosemide, bumetadine, torsemide, or hydrochlorothiazide. Diuretic doses were available on 222 patients. For the purposes of between-group comparisons, the doses for patients on loop diuretics $(n=197)$ were converted to furosemide equivalents using the following formula: furosemide $=1 \mathrm{mg}$, bumetadine $=0.0375 \mathrm{mg}$, and torsemide $=0.5 \mathrm{mg} .{ }^{18}$ The remainder $(\mathrm{n}=25)$ were prescribed hydrochlorothiazide and compared separately.

Event-free survival-The primary outcome of this study was defined as the composite end-point of time to first event of emergency department (ED) visit or hospitalization for HF or other cardiac-related cause and all-cause mortality during the 12-month follow-up period. Patients were asked to report ED visits and hospitalizations during monthly telephone follow-up interviews and their responses were confirmed by review of hospital records. Data regarding death were collected from interviews with family members or physicians and were confirmed by review of medical records and death certificates.

\section{Procedure}

This study was approved by the Institutional Review Boards at each site. Eligible patients were referred by cardiologists and nurse practitioners to the investigators. Trained research assistants explained the purposes and procedures for the study and written informed consent was obtained. Patients were visited in their home to provide urine collection equipment with detailed written and verbal instructions for the 24-hour collection procedure. They were also instructed to continue their normal eating and drinking habits. No patients were placed on fluid restriction by their health care provider during the study period. To insure accurate and complete urine collection, a research assistant called patients the morning urine collection began to review the procedure and remind them of start and end times for urine collection. Patients recorded volume and time of each void in a log. The logs and urine container were brought by patients to the GCRC the morning of 24-hour urine collection completion. Research nurses verified data on clinical variables and completeness of 24-hour urine 
collection. Patients were followed by telephone interview every month for 12 months to collect event-free survival data.

\section{Statistical Analysis}

Data analyses were performed using SPSS for Windows 16.0. Descriptive statistics including frequencies with percents and means with standard deviations were used to describe patient characteristics. For the purpose of using UNa as an estimate of dietary sodium intake, $\mathrm{UNa}$ in mmoles was converted to $\mathrm{mg}(\mathrm{mg}=\mathrm{mmole} \times 22.99)$. Patients were stratified into NYHA Class I/II and III/IV and grouped within each stratum using a $3 \mathrm{~g} 24-$ hour UNa cut point. Differences in event-free survival between groups within each stratum was tested using a Cox proportional hazards model while controlling for age, gender, HF etiology, BMI, LVEF, and total comorbidity score. A hazard ratio (HR) for event-free survival was obtained for all independent variables along with $95 \%$ confidence intervals (CIs).

\section{RESULTS}

\section{Sample characteristics}

Sample characteristics are shown in Table 1 . The majority of patients were over 65 years old with a range of 23 to 97 years. Over a half of the patients were obese. As a group, patients were primarily in NYHA functional class II and III. There were no differences in frequency of prescribed medications or in diuretic doses between the stratified groups. Other patient characteristics were similar except those in NYHA Class I/II had a slightly higher mean LVEF and a lower total comorbidity score than patients in III/IV.

\section{4-hour UNa as an indicator of dietary sodium intake}

Sixty-six percent of patients had 24-hour UNa excretion that indicated a daily sodium intake of more than $3 \mathrm{~g}$. There was no difference in mean UNa between NYHA class I/II and class III/IV (Fig. 1). Similarly, there was no difference in event-rates between NYHA class I/II and III/IV.

\section{4-hour UNa and event-free survival}

Over the median follow-up period of 12 months, 59 patients were hospitalized, 11 had ED visits for decompensated HF or other cardiac-related problems, and 7 patients died. Table 2 presents a comparison of events between NYHA class I/II and NYHA class III/IV.

The Cox proportional hazards models are presented in Table 3. Patients in NYHA class I/II with a 24-hour UNa greater than $3 \mathrm{~g}$ had longer event-free survival than patients with $\mathrm{UNa}$ less than $3 \mathrm{~g}$ (hazard ratio $[\mathrm{HR}]=0.44,95 \%$ confidence interval $[\mathrm{CI}]=0.20-0.97$ ) controlling for age, gender, etiology of HF, BMI, LVEF, and total comorbidity score (Figure 2). In contrast, patients in NYHA class III/IV with a 24-hour UNa greater than $3 \mathrm{~g}$ had shorter event-free survival than patients with $\mathrm{UNa}$ less than $3 \mathrm{~g}(\mathrm{HR}=2.54,95 \% \mathrm{CI}=1.10$ 5.84) (Figure 3) controlling for the same variables.

\section{DISCUSSION}

To the best of our knowledge, this was the first prospective study to demonstrate that a specific level of sodium intake was associated with event-free survival of patients with HF. The most surprising finding was the differences in event-free survival between NYHA functional classes using the $3 \mathrm{~g}$ UNa cut point. Unexpectedly, patients at NYHA class I/II with UNa less than $3 \mathrm{~g}$ had shorter event-free survival than NYHA class I/II patients with higher UNa. More consistent with the current understanding of the effects of sodium intake 
on outcomes, patients classified as NYHA Class III/IV with UNa above $3 \mathrm{~g}$ had shorter event-free survival than NYHA class III/IV with lower UNa.

It is not possible to determine from our data the mechanisms responsible for the contrasting results. However, we suggest the following as one potential explanation. The majority of patients were prescribed diuretics, ACE inhibitors, and/or angiotensin II receptor blockers (ARB) and aldosterone antagonists. Diuretics were prescribed to enhance sodium excretion, normalize sodium balance, and decrease fluid retention. ${ }^{5}$ In patients at NYHA class I/II, these drugs may be sufficiently effective that restriction of dietary sodium results in a sodium deficit that triggers the renin-angiotensin aldosterone system limiting the effectiveness of ACE inhibitors, ARBs, aldosterone antagonists. In contrast, diuretics may be less effective in more symptomatic patients at NYHA Class III/IV making sodium restriction necessary to prevent fluid retention and minimize risk of exacerbation.

There are data to support the hypothesis that sodium restriction may trigger compensatory responses in medically stable patients with HF. Paterna et al., ${ }^{11}$ enrolled 232 NYHA class II patients 30 days post-discharge from a hospitalization for decompensated HF. The patients were randomized into two groups. One group $(n=114)$ received a $1.8 \mathrm{~g}$ sodium diet and the other group $(n=118)$ a 2.8 g sodium diet. Patients were placed on either a 1 or $2 \mathrm{~L}$ fluid restriction and prescribed 250 to $500 \mathrm{mg}$ of furosemide daily. Over the 180 day study period, patients in the $1.8 \mathrm{~g}$ sodium intake group had a higher readmission rate. At 180 days, the 1.8 $\mathrm{g}$ sodium diet group had an average B-type natriuretic peptide level $350 \mathrm{pg} / \mathrm{ml}$ higher in than in the $2.8 \mathrm{~g}$ sodium diet. Aldosterone levels were also higher in the $1.8 \mathrm{~g}$ sodium diet group averaging nearly double the levels of the $2.8 \mathrm{~g}$ sodium diet group. Similarly, the $1.8 \mathrm{~g}$ sodium diet group experienced a $44 \%$ increase in plasma rennin activity from baseline while those in the $2.7 \mathrm{~g}$ sodium diet group had no change in plasma rennin activity over 180 days. In a subsequent 12 month study using the same protocol, similar neurohormonal activation and higher rates of hospital admissions or death were evident in patients on a $1.8 \mathrm{~g}$ sodium diet compared to patients on a 2.8 gram diet. ${ }^{19}$ At 12 months, patients on the 1.8 gram diet had significantly higher levels of the proinflammatory cytokines tumor necrosis factor- $\alpha$, and interleukin- 6 and lower levels of the anti-inflammatory cytokine interleukin-10 than patients on a $2.8 \mathrm{~g}$ sodium diet. These results are consistent with the hypothesis that sodium restriction can trigger compensatory neuroendocrine and inflammatory responses in NYHA class II patients that could lead to hospitalization for HF exacerbation.

Damgaard et al. ${ }^{20}$ compared body weight, plasma volume, hemodynamic and neuroendocrine responses, and urinary sodium excretion in a small group of 12 male patients with compensated HF to a group of age-matched healthy controls after 7 days on a $5.7 \mathrm{~g}$ vs.1.6 g sodium diet. Patients with HF had a comparable increase in body weight and expansion in plasma volume on the $5.7 \mathrm{~g}$ diet as the healthy controls. Urinary sodium excretion of patients with HF was the same as healthy controls at both $5.7 \mathrm{~g}$ and $1.6 \mathrm{~g}$ dietary sodium intake indicating patients did not retain sodium while on the $5.7 \mathrm{~g}$ sodium diet. The expansion of plasma volume in patients with HF on the $5.7 \mathrm{~g}$ diet was accompanied by higher stroke volume and lower resting heart rate and total peripheral resistance compared to the $1.6 \mathrm{~g}$ diet. Norepinephrine, epinephrine, and angiotensin II levels were all significantly lower in patients with HF while on the $5.7 \mathrm{~g}$ diet than while on the 1.6 $\mathrm{g}$ diet. Pro-B-type natriuretic peptide levels in patients with HF did not differ between the two diet conditions. These data suggest that a higher sodium diet in patients with compensated HF is associated with better cardiovascular function and decreased neuroendocrine activity both of which should lead to longer event-free survival.

The average 24-hour UNa was $4.1 \mathrm{~g}$ in this study and less than $15 \%$ of patients had a UNa that indicated sodium intake less than $2 \mathrm{~g}$ per day. Considering that the upper range of 
sodium intake of healthy Americans is $4.1 \mathrm{~g},{ }^{22}$ this finding reflects that the SRD was rarely followed by patients in this study. Indeed, patients with HF have considerable difficulty initiating and maintaining a SRD. ${ }^{23}$ Neily and colleagues ${ }^{24}$ reported that only $14 \%$ of the patients with HF were aware of the guideline for a SRD. Additionally, most patients with HF state they do not know the best methods for limiting sodium in the diet. ${ }^{12,}{ }^{23}$ The information given by health care providers has been reported to be insufficient to patients to understand how to follow a SRD. ${ }^{25} 26$ Among the barriers to adherence, patients have identified the lack of sound rationale for the SRD. ${ }^{24-26}$ The provision of an evidence-based level of sodium intake and the link between worsening symptoms and non-adherence to the SRD could address this barrier and may improve adherence.

\section{Limitations}

Although 24-hour UNa has been shown to be a good measure of dietary sodium intake, UNa works best in stable patients who have normal fluid and sodium balance. Patients with HF have altered hormonal responses that can lead to fluid and sodium retention. This may make $\mathrm{UNa}$ an unreliable indictor of dietary sodium intake. However, diuretics, ACE inhibitors, and aldosterone antagonists are provided to normalize sodium and fluid balance in patients with HF. We recruited patients who were weight stable and had been on the same doses of all medications for three month before enrollment indicating stable fluid and sodium balances. In these patients, sodium excretion can be assumed to be a reliable marker of dietary sodium intake. This assumption is supported by data that show patients with compensated HF have the same urinary sodium excretion as healthy controls over a wide range of dietary sodium intake. ${ }^{20} \mathrm{We}$ also note that 24-hour urine was measured one time. Therefore, this single 24-hour urinary sodium excretion may not reflect long-term sodium intake. Finally, stratifying patients by different markers of heart failure severity may provide additional insight.

\section{Conclusion}

Prior researchers demonstrating worse event-free survival in patients on low sodium diets included fluid restrictions and diuretic doses that are not reflective of the typical patient with HF. ${ }^{11}, 19$ The study in which patients with medically compensated HF showed no evidence of sodium retention and better hemodynamic responses while consuming a high sodium diet was short term with no event-free survival data. ${ }^{20}$ None of these studies included comparisons of patients with different levels of HF severity. Our data demonstrated that patients in NYHA class III/IV with dietary sodium intake greater than $3 \mathrm{~g}$ were approximately two and half times more likely to be hospitalized for cardiac problems or die after controlling for key clinical variables. This finding is consistent with current recommendations. Conversely, sodium intake less than $3 \mathrm{~g}$ was associated with higher risk for hospitalization and death in patients at NYHA class I/II. This finding suggests that sodium restriction may not be effective for some patients with less symptomatic heart failure. Clearly, additional research is needed to clarify the role of dietary sodium restriction in management of patients at different stages of HF before definitive recommendations can be made. Evidence suggests that future studies will need to consider diuretic dose in conjunction with level of sodium intake ${ }^{21}$ to provide a full understanding of the interaction between sodium intake and medical management of patients with HF.

\section{Acknowledgments}

The authors would like to acknowledge the following for their contribution to the conduct of this study. JinShil Kim, PhD, RN, Ajou University, South Korea; Heather Jaynes, RN, MSN, Rebecca Sloan, PhD, RN, and Ms. Laura Parker, Indiana University School of Nursing; Armina Gradus-Pizlo, MD, Director, Advanced Heart Care Program, Clarian Health Partners, Indianapolis, IN; Joan Barr, RN, MSN, Advanced Heart Care Program, Clarian Health 
Partners; and Heather Payne Emerson, PhD, RD, Murray State University. This study was supported in part by a grant from NIH NINR R01 NR 009280, General Clinical Research Centers at University of Kentucky: M01RR02602, Emory University: M01RR0039, and Indiana University: MO1 RR000750 and by NIH, NINR Center grant 1P20NR010679 to the University of Kentucky College of Nursing. The content is solely the responsibility of the authors and does not necessarily represent the official views of the National Institute of Nursing Research or the National Institutes of Health.

\section{References}

1. United States Department of Agriculture. Dietary guidelines for Americans. 2005. Available at: www.healthierus.gov/dietaryguidelines.

2. Lichtenstein AH, Appel LJ, Brands M, Carnethon M, Daniels S, Franch HA, et al. Diet and lifestyle recommendations revision 2006: A scientific statement from the American Heart Association Nutrition Committee. Circulation. 2006; 114:82-96. [PubMed: 16785338]

3. Adams KF, Lindenfeld J, Arnold JMO, Baker DW, Barnard DH, Baughman KL, et al. HFSA 2006 Comprehensive Heart Failure Practice Guideline. J Card Fail. 2006; 12:e1-e122. [PubMed: 16500560]

4. Hunt, SA.; Abraham, WT.; Chin, MH.; Feldman, AM.; Francis, GS.; Ganiats, TG., et al. ACC/AHA 2005 guideline update for the diagnosis and management of chronic heart failure in the adult: A report of the American College of Cardiology/American Heart Association Task Force on Practice Guidelines (Writing Committee to Update the 2001 Guidelines for the Evaluation and Management of Heart Failure). [Accessed September 2005]. Available at: http://www.acc.org/clinical/guidelines/failure//index.pdf.

5. Hunt SA, Abraham WT, Chin MH, Feldman AM, Francis GS, Ganiats TG, et al. 2009 focused update incorporated into the ACC/AHA 2005 Guidelines for the Diagnosis and Management of Heart Failure in Adults: A report of the American College of Cardiology Foundation/American Heart Association Task Force on Practice Guidelines: Developed in collaboration with the International Society for Heart and Lung Transplantation. Circulation. 2009; 119:e391-e479. [PubMed: 19324966]

6. Dickstein K, Cohen-Solal A, Filippatos G, McMurray JJ, Ponikowski P, Poole-Wilson PA, et al. ESC Guidelines for the diagnosis and treatment of acute and chronic heart failure 2008: The Task Force for the Diagnosis and Treatment of Acute and Chronic Heart Failure 2008 of the European Society of Cardiology. Developed in collaboration with the Heart Failure Association of the ESC (HFA) and endorsed by the European Society of Intensive Care Medicine (ESICM). Eur Heart J. 2008; 29:2388-2442. [PubMed: 18799522]

7. Bennett SJ, Huster GA, Baker SL, Milgrom LB, Kirchgassner A, Birt J, et al. Characterization of the precipitants of hospitalization for heart failure decompensation. Am J Crit Care. 1998; 7:168174. [PubMed: 9579241]

8. Michalsen A, Konig G, Thimme W. Preventable causative factors leading to hospital admission with decompensated heart failure. Heart. 1998; 80:437-441. [PubMed: 9930040]

9. Opasich C, Febo O, Riccardi PG, Traversi E, Forni G, Pinna G, et al. Concomitant factors of decompensation in chronic heart failure. Am J Cardiol. 1996; 78:354-357. [PubMed: 8759821]

10. Tsuyuki RT, McKelvie RS, Arnold JM, Avezum A Jr, Barretto AC, Carvalho AC, et al. Acute precipitants of congestive heart failure exacerbations. Arch Intern Med. 2001; 161:2337-2342. [PubMed: 11606149]

11. Paterna S, Gaspare P, Fasullo S, Sarullo FM, Di Pasquale P. Normal-sodium diet compared with low-sodium diet in compensated congestive heart failure: Is sodium an old enemy or a new friend? Clin Sci (Lond). 2008; 114:221-230. [PubMed: 17688420]

12. Chung ML, Moser DK, Lennie TA, Worrall-Carter L, Bentley B, Trupp R, et al. Gender differences in adherence to the sodium-restricted diet in patients with heart failure. J Card Fail. 2006; 12:628-634. [PubMed: 17045182]

13. Espeland MA, Kumanyika S, Wilson AC, Reboussin DM, Easter L, Self M, et al. Statistical issues in analyzing 24-hour dietary recall and 24-hour urine collection data for sodium and potassium intakes. Am J Epidemio. 2001; 153:996-1006. 
14. Bates, CJ.; Thurnham, DI.; Bingham, SA.; Margetts, BM.; Nelson, M. Biochemical markers of nutrient intake. In: Margetts, BM.; M, N., editors. Design in nutritional epidemiology. Oxford, England: Oxford University Press; 1997. p. 170-240.

15. McKeown NM, Day NE, Welch AA, Runswick SA, Luben RN, Mulligan AA, et al. Use of biological markers to validate self-reported dietary intake in a random sample of the European Prospective Investigation into Cancer United Kingdom Norfolk cohort. Am J Clin Nutr. 2001; 74:188-196. [PubMed: 11470719]

16. Korhonen MH, Litmanen H, Rauramaa R, Vaisanen SB, Niskanen L, Uusitupa M. Adherence to the salt restriction diet among people with mildly elevated blood pressure. Eur J Clin Nutr. 1999; 53:880-885. [PubMed: 10557001]

17. Charlson ME, Pompei P, Ales KL, MacKenzie CR. A new method of classifying prognostic comorbidity in longitudinal studies: development and validation. J Chronic Dis. 1987; 40:373383. [PubMed: 3558716]

18. Eshaghian S, Horwich TB, Fonarow GC. Relation of loop diuretic dose to mortality in advanced heart failure. Am J Cardiol. 2006; 97:1759-1764. [PubMed: 16765130]

19. Parrinello G, Di Pasquale P, Licata G, Torres D, Giammanco M, Fasullo S, et al. Long-term effects of dietary sodium intake on cytokines and neurohormonal activation in patients with recently compensated congestive heart failure. J Card Fail. 2009; 15:864-873. [PubMed: 19944363]

20. Damgaard M, Norsk P, Gustafsson F, Kanters JK, Christensen NJ, Bie P, et al. Hemodynamic and neuroendocrine responses to changes in sodium intake in compensated heart failure. Am J Physiol Regul Integr Comp Physiol. 2006; 290:R1294-R1301. [PubMed: 16357094]

21. Bonfils PK, Damgaard M, Taskiran M, Goetze JP, Norsk P, Gadsboll N. Impact of diuretic treatment and sodium intake on plasma volume in patients with compensated systolic heart failure. Eur J Heart Fai. 2010; 12:995-1001.

22. Department of Agriculture ARS. Nutrient intakes from food: Mean amounts consumed per individual, one day. 2005-2006 [Accessed November 1, 2010]. Available at: www.ars.usda.gov/ba/bhnrc/fsrg.

23. Moser DK, Doering LV, Chung ML. Vulnerabilities of patients recovering from an exacerbation of chronic heart failure. Am Heart J. 2005; 150:984. [PubMed: 16290979]

24. Neily JB, Toto KH, Gardner EB, Rame JE, Yancy CW, Sheffield MA, et al. Potential contributing factors to noncompliance with dietary sodium restriction in patients with heart failure. Am Heart J. 2002; 143:29-33. [PubMed: 11773909]

25. Bentley B, De Jong MJ, Moser DK, Peden AR. Factors related to nonadherence to low sodium diet recommendations in heart failure patients. Eur J Cardiovasc Nurs. 2005; 4:331-336. [PubMed: 15935733]

26. Sheahan SL, Fields B. Sodium dietary restriction, knowledge, beliefs, and decision-making behavior of older females. J Am Acad Nurse Pract. 2008; 20:217-224. [PubMed: 18387019] 


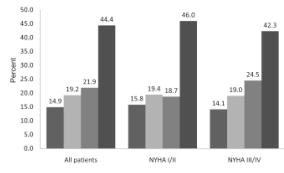

Fig 1.

24-hour Urinary Sodium Excretion 


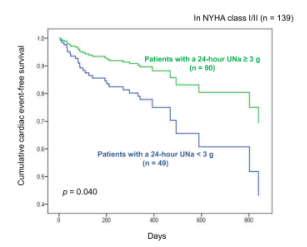

Fig 2.

Adjusted differences in cardiac event-free survival between patients above and below the cutpoint of $3 \mathrm{~g}$ for 24-hour urinary sodium excretion in NYHA class I/II 


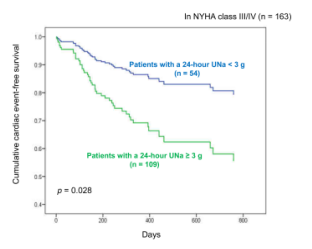

Fig 3.

Adjusted differences in cardiac event-free survival between patients above and below the cutpoint of $3 \mathrm{~g}$ for 24-hour urinary sodium excretion in NYHA class III/IV

1. Damgaard M, Norsk P, Gustafsson F, Kanters JK, Christensen NJ, Bie P, Friberg L, Gadsboll N. Hemodynamic and neuroendocrine responses to changes in sodium intake in compensated heart failure. Am J Physiol Regul Integr Comp Physiol. 2006;290(5):R12941301. 
Table 1

Patient Characteristics

\begin{tabular}{|c|c|c|c|c|}
\hline \multirow[b]{2}{*}{ Characteristi } & & \multicolumn{3}{|c|}{$\mathbf{N}(\%)$ or Mean $( \pm \mathrm{SD})$} \\
\hline & & $\begin{array}{c}\text { Total } \\
\mathbf{N}=302\end{array}$ & $\underset{(n=139)}{\text { NYHA I/II }}$ & $\begin{array}{c}\text { NYHA III/IV } \\
\quad(n=163)\end{array}$ \\
\hline \multicolumn{2}{|l|}{ Age (years) } & $62( \pm 12)$ & $62( \pm 12)$ & $62( \pm 12)$ \\
\hline \multirow[t]{2}{*}{ Gender } & Male & $203(67.2)$ & $97(69.8)$ & $106(65.0)$ \\
\hline & Female & $99(32.8)$ & $42(30.2)$ & $57(35.0)$ \\
\hline \multicolumn{2}{|c|}{ Body mass index $\left(\mathrm{kg} / \mathrm{m}^{2}\right)$} & $31.0( \pm 7.2)$ & $30.5( \pm 6.8)$ & $31.4( \pm 7.4)$ \\
\hline & Normal weight $(<25)$ & $65(21.5)$ & $31(22.3)$ & $34(20.9)$ \\
\hline & Overweight $(25-29.9)$ & $78(25.9)$ & $37(26.6)$ & $41(25.2)$ \\
\hline & Obese $(\geq 30)$ & $159(52.6)$ & $71(51.1)$ & $88(54.0)$ \\
\hline \multirow[t]{2}{*}{ HF etiology } & Non-ischemic heart disease & $158(52.3)$ & $79(56.8)$ & $79(48.5)$ \\
\hline & Ischemic heart disease & $144(47.7)$ & $60(43.2)$ & $84(51.5)$ \\
\hline \multicolumn{2}{|c|}{ Left ventricular ejection fraction (\%) } & $33.8( \pm 14.0)$ & $35.5( \pm 13.2)$ & $32.3( \pm 14.5)^{*}$ \\
\hline \multicolumn{2}{|c|}{ Total comorbidity score } & $3.1( \pm 2.0)$ & $2.7( \pm 1.8)$ & $3.4( \pm 2.2)^{*}$ \\
\hline \multirow[t]{6}{*}{ Medication } & ACE inhibitors & $215(71.2)$ & 99 (71.7) & $116(71.2)$ \\
\hline & Angiotension II receptor blocker & $49(16.2)$ & $24(17.3)$ & $25(15.5)$ \\
\hline & Digoxin & $96(31.8)$ & $37(26.8)$ & $59(36.4)$ \\
\hline & $\beta$-blocker & $266(88.1)$ & $119(85.6)$ & $147(90.2)$ \\
\hline & Diuretics & $238(78.8)$ & $106(76.3)$ & $132(82.0)$ \\
\hline & Aldosterone antagonist & $63(20.9)$ & $26(20.0)$ & $37(23.3)$ \\
\hline \multirow{2}{*}{\multicolumn{2}{|c|}{ Serum sodium $(\mathrm{mmol} / \mathrm{L})$}} & $(\mathrm{n}=175)$ & $(\mathrm{n}=84)$ & $(n=91)$ \\
\hline & & $139( \pm 3)$ & $139( \pm 2)$ & $139( \pm 3)$ \\
\hline \multicolumn{2}{|l|}{ Diuretic dose } & $(\mathrm{n}=197)$ & $(\mathrm{n}=83)$ & $(n=114)$ \\
\hline \multirow{2}{*}{\multicolumn{2}{|c|}{ Furosemide equivalent (mg) }} & $54( \pm 45)$ & $51( \pm 50)$ & $61( \pm 45)$ \\
\hline & & $(n=25)$ & $(n=15)$ & $(\mathrm{n}=10)$ \\
\hline \multicolumn{2}{|c|}{ Hydrochlorothiazide (mg) } & $21( \pm 6)$ & $22( \pm 6)$ & $20( \pm 7)$ \\
\hline
\end{tabular}

ACE: angiotensin-converting enzyme, HF: heart failure, NYHA: New York Heart Association functional class. ${ }^{*} p 0.05$ by independent t-test between NYHA classes I/II vs. III/IV. 
Table 2

Event-rates and median time to first event in patients classified as NYHA I/II and NYHA III/IV

\begin{tabular}{lrrr}
\hline & $\begin{array}{r}\text { Total } \\
(\mathbf{N}=\mathbf{3 0 2})\end{array}$ & $\begin{array}{r}\text { NYHA I/II } \\
(\mathbf{n}=\mathbf{1 3 9})\end{array}$ & $\begin{array}{r}\text { NYHA III/IV } \\
(\mathbf{n}=\mathbf{1 6 3})\end{array}$ \\
\hline All-cause death & $7(2.3)$ & $4(2.9)$ & $3(1.8)$ \\
Cardiac-related hospitalization & $59(19.5)$ & $22(15.8)$ & $37(22.7)$ \\
Cardiac-related emergency department visit & $11(3.6)$ & $4(2.9)$ & $7(4.3)$ \\
$\quad$ Total Events & $77(25.4)$ & $30(21.6)$ & $47(28.8)$ \\
Median time to first event (days) & $141(80,297)$ & $125(49,333)$ & $144(83,250)$ \\
\hline
\end{tabular}

Values are $\mathrm{n}(\%)$ or median $\left(25^{\text {th }}, 75^{\text {th }}\right.$ quartile). NYHA: New York Heart Association functional class 
